\title{
Concurrent acquired inhibitors to factor VIII and IX, a laboratory artifact: a case report
}

\author{
Saša Anžej Doma*1, Andreas Hillarp², Tadej Pajič', Dušan Andoljšek'1, Peter Černelč Peter ${ }^{1}$, Irena Preložnik Zupan¹ \\ ${ }^{1}$ Department of Hematology, University Medical Centre Ljubljana, Slovenia \\ 2Department of Clinical Chemistry and Transfusion Medicine, Halland Hospital, Halmstad, Sweden; at the time of the investigation \\ working at the Coagulation laboratory of Malmö Centre for Thrombosis and Haemostasis, Skane University Hospital, Malmö, Sweden
}

*Corresponding author: sasa_anzej@yahoo.co.uk

\begin{abstract}
Acquired inhibitors to coagulation factors other than factor VIII are extremely rare. We describe a case of a 59-year-old woman with abnormal bleeding, diagnosed with concurrent inhibitor antibodies to factor VIII and IX by Bethesda testing. We demonstrate that anti-FVIII antibodies of a very high titre are capable of disturbing the aPTT-based Bethesda assay, resulting in falsely-positive antibodies to factor IX. The case also illustrates the usefulness of the immunological assay (ELISA) in complementing the inhibitor diagnosis.
\end{abstract}

Key words: inhibitor; autoantibody; blood coagulation factor; enzyme-linked immunosorbent assay

\section{Introduction}

Acquired haemophilia is a rare condition caused by production of autoantibodies which inactivate coagulation factors. Inhibitors are most commonly directed to factor (F) VIII (incidence of 1,4 per million), a condition known as acquired haemophilia A (1). Inhibitors to other coagulation factors are much less common $(2,3)$. In $50 \%$ of cases, FVIII autoantibodies occur in patients lacking any relevant concomitant disease; the remaining cases may be associated with postpartum period, autoimmune diseases, underlying malignancy or precancerous states, infections, vaccinations or use of medications (4). An acquired inhibitor should be considered in patients with a recent onset of abnormal, often large bleeding, without prior bleeding diathesis $(3,5)$. Typical laboratory findings in acquired haemophilia are abnormal coagulation screening tests, that do not correct with normal plasma, either with immediate or incubated mix. The diagnosis is confirmed by assays of specific factors and demonstration of an inhibitor, using the original or
Nijmegen-modified Bethesda assay $(1,3)$. Treatment is directed to both the control of bleeding and the elimination of the inhibitor (4).

The aim of this case report is a presentation of a patient with acquired haemophilia with apparent antibodies against both FVIII and FIX. Our hypothesis was that the finding of autoantibodies against more than one coagulation factor is very rare so inhibitors to FIX in our case were probably a false finding.

\section{Materials and methods}

\section{Blood sampling}

Blood samples of the patient for coagulation assays were taken into $4.5 \mathrm{~mL}$ BD Vacutainer tubes with $0.105 \mathrm{M}$ trisodium citrate (Beckton, Dickinson and Company, Plymouth, United Kingdom). The blood to additive ratio was 9:1. Platelet-poor plasma was prepared by centrifugation at $2000 \times \mathrm{g}$ for 
15 minutes at $4{ }^{\circ} \mathrm{C}$ in a standard bench cooling centrifuge (Multifuge $3 \mathrm{~S}-\mathrm{R}$, Heraeus, ThermoScientific, USA) (6). The first part of the laboratory work was done in a specialized haematology laboratory, Department of Haematology, University Medical Centre Ljubljana, Slovenia. Small aliquots of samples $(0.5 \mathrm{~mL})$ were frozen at $-20{ }^{\circ} \mathrm{C}$ and for long-term storage at $-80^{\circ} \mathrm{C}$. Some aliquots of frozen samples were sent to Laboratory of Centre for Thrombosis and Haemostasis, Skåne University Hospital in Malmö, Sweden, for further analysis.

\section{Methods}

To detect immediate or time dependent inhibition, normal plasma (Instrumentation Laboratory, Bedford, USA) and test plasma samples were tested for activated partial thromboplastin time (aPTT) immediately after mixing (50:50) and also after incubation at $37^{\circ} \mathrm{C}$ for $120 \mathrm{~min}$ (6). FVIII, FIX, FXI and FXII activities were measured by one-stage aPTTbased assay. Hemosil Calibration plasma, Hemosil APTT-SP (liquid) reagent and Hemosil factor FVIII, FIX, FXI and FXII deficiency plasma from Instrumentation Laboratory (Bedford, USA) were used for preparing calibration curves and sample testing. Screening (Hemosil LAC Screen, Bedford, USA) and confirmatory (Hemosil LAC Confirm, Bedford, USA) test based on dilute Rusell's Viper Venom Time were used for exclusion of lupus anticoagulants. All procedures were carried out according to manufacturer's instructions.

In Ljubljana, Bethesda assay (6) was used to quantify FVIII and FIX inhibitors. Dilutions of test plasma were incubated with an equal volume of the normal plasma pool (Hemosil Calibration plasma, Bedford, USA) at $37{ }^{\circ} \mathrm{C}$. The normal pool plasma was taken to represent 1 unit of FVIII. Dilutions of a control normal plasma (Hemosil Calibration plasma, Bedford, USA) containing no inhibitor were treated in the same way. An equal volume of normal plasma mixed with buffer (Hemosil Factor diluent, Bedford, USA) was taken to represent the $100 \%$ value. At the end of the incubation period, the residual factor was assayed and the inhibitor strength was calculated from a standard graph of residual factor activity versus inhibitor units. The cut-off for positivity was set at $0.6 \mathrm{BU} / \mathrm{mL}$. All co- agulation tests were performed on the ACL TOP automated coagulation analyser (Instrumentation Laboratory, Bedford, USA).

In Malmö coagulation laboratory inhibitory antibodies against FVIII, FIX and FXII were analysed using the Nijmegen modified Bethesda assay (7). The cut-off for a positive inhibitory antibody was set at $>0.4 \mathrm{BU} / \mathrm{mL}$.

In addition, anti-human lgG specific enzymelinked immunosorbent assays (ELISA) were performed in a manner previously described (8), using recombinant FVIII or FIX concentrates as antigens in separate assays. The cut-off for positivity was calculated based on the mean optical density +3 standard deviations of samples from ten healthy individuals used as controls on each plate. All positive samples were analysed at least twice.

Diagnostic work-up for possible underlying disorders of the patient comprised of: history taking, clinical examination, laboratory tests including tumor markers, serological and immunological tests for autoimmune and infective diseases, x-ray of the chest and ultrasound of the abdomen.

An informed consent was obtained from the patient's son before presenting the collected data as a case report.

The approval from the national Medical Ethics Committee has been obtained.

\section{Case presentation}

A 59-year-old, previously healthy female patient was admitted to the traumatology department of the University Medical Centre Ljubljana, Slovenia after left femur neck fracture in a motorcycle accident. An unexplained coagulopathy was observed during and after surgery, causing vaginal bleeding and extensive haematomas of the right elbow, upper arm, and the right inguinal region. In the screening haemostasis tests we noticed a normal platelet count $\left(197 \times 10^{9} / \mathrm{L}\right)$, a normal thrombin time of $15.5 \mathrm{~s}$, a prolonged aPTT of $80.6 \mathrm{~s}$ and a normal prothrombin time of 0.85 ; mixing studies revealed inhibitors. FVIII and FIX activities were both under $0.01 \mathrm{IU} / \mathrm{mL}$, with inhibitor titres of 358 $\mathrm{BU} / \mathrm{mL}$ and $6 \mathrm{BU} / \mathrm{mL}$, respectively. At first blood 
drawing we also measured low FXI $(<0.01 \mathrm{IU} / \mathrm{mL})$ and FXII (0.02 IU/mL). Lupus anticoagulants were excluded. The patient was given recombinant factor VIla (NovoSeven ${ }^{\circledR}$, NovoNordisk, A/S, Bagsvaerd, Denmark) to control the bleeding, at the same time the immunosuppression with methylprednisolone $1 \mathrm{mg} / \mathrm{kg}$ and cyclophosphamide 100 $\mathrm{mg}$ daily was started. Because of considerable blood loss, she received several transfusions of red blood cells. In two weeks' time we noticed a subsequent decline of the inhibitors, from the maximum of $389 \mathrm{BU} / \mathrm{mL}$ to $109 \mathrm{BU} / \mathrm{mL}$ for FVIII, and from the maximum of $7 \mathrm{BU} / \mathrm{mL}$ to $0 \mathrm{BU} / \mathrm{mL}$ for FIX. There were no signs of underlying malignancy, autoimmune diseases or infections, and no offending drugs. The results of concurrent inhibitors to FVIII and to FIX, the latter in a much lower titre than inhibitors to FVIII, detected in Ljubljana laboratory by Bethesda assay, are presented in Figure 1.

By using the Bethesda-Nijmegen assay in Malmö, dual inhibitors in the initial blood samples of our patient were confirmed. Again, FVIII inhibitor titres were much higher (from 73 to $217 \mathrm{BU} / \mathrm{mL}$ ) than FIX inhibitor titres (2.5 to $4 \mathrm{BU} / \mathrm{mL}$ ).

ELISA, using recombinant FIX and FVIII concentrates as antigens, revealed positive antibodies against FVIII only.

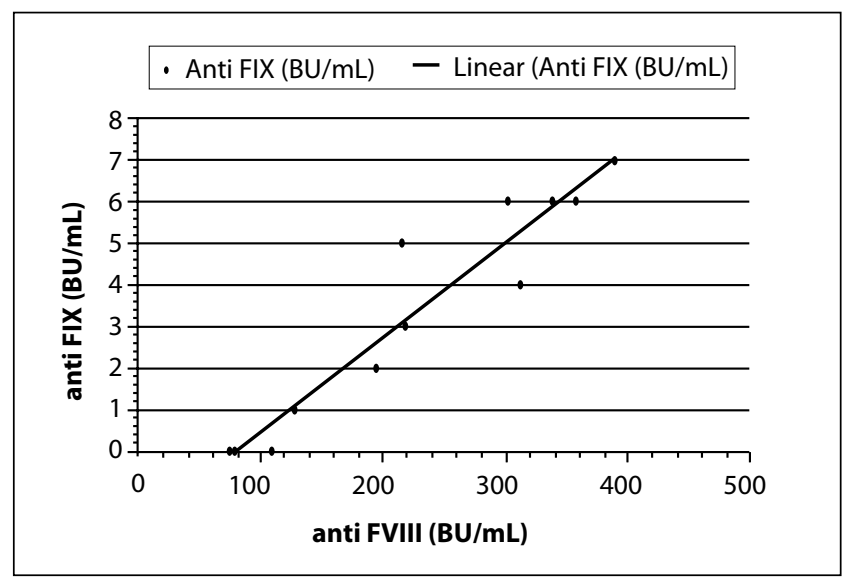

FIgURE 1. Titres of anti-FVIII and anti-FIX antibodies in our patient, measured by Bethesda assay in Ljubljana. Titres of antiFVIII approximately $110 \mathrm{BU} / \mathrm{mL}$ and higher are accompanied by anti-FIX titres, although in a much lower titre (assuming that the cut-off for positive anti-FIX is $0.6 \mathrm{BU} / \mathrm{mL}$ ). A dose-dependent effect of anti-FVIII antibodies on the anti-FIX assay is demonstrated by a linear line.
TABLE 1. Inhibitor antibodies of our patient (Samples No.1-4) and the "Malmö patient", measured by Bethesda-Nijmegen assay and ELISA assay in Malmö coagulation laboratory

\begin{tabular}{lccccc}
\hline Samples & $\begin{array}{c}\text { anti- } \\
\text { FVIII } \\
\text { (BU/mL) }\end{array}$ & $\begin{array}{c}\text { anti- } \\
\text { FIX } \\
\text { (BU/mL) }\end{array}$ & $\begin{array}{c}\text { anti- } \\
\text { FVIII } \\
\text { (ELISA) }\end{array}$ & $\begin{array}{c}\text { anti- } \\
\text { FIX } \\
\text { (ELISA) }\end{array}$ & $\begin{array}{c}\text { anti- } \\
\text { FXII } \\
\text { (BU/mI) }\end{array}$ \\
\hline No.1 & 152 & 2.5 & pos & neg & ND \\
No.2 & 204 & 4 & pos & neg & 4 \\
No.3 & 217 & 4 & pos & neg & ND \\
No.4 & 73 & 0 & pos & neg & ND \\
“Malmo & & & & & \\
patient” & 1429 & 14 & pos & neg & ND \\
\hline
\end{tabular}

Samples No. 1-4 were taken from our patient on day 1 (Sample No.1), day 4 (Sample No.2), day 5 (Sample No.3) and day 14 (Sample No.4) of treatment. "Malmö patient"- a patient from the Malmö coagulation laboratory with a very high FVIII inhibitor titre. ND - not determined, pos - positive, neg negative.

Subsequently, a Bethesda-Nijmegen mixing experiment with FXII-deficient plasma instead of FIX was performed; again a positive anti-FXII titre of 4 $\mathrm{BU} / \mathrm{mL}$ was found, exactly the same as obtained previously for FIX. Additionally, a sample from another patient with a very high anti-FVIII inhibitor titre of $1429 \mathrm{BU} / \mathrm{mL}$ from the Malmö hospital ("Malmö patient" in Table 1) was analysed and resulted in an anti-FIX Bethesda titre of $14 \mathrm{BU} / \mathrm{mL}$.

The results of our patient's samples, together with the "Malmö patient", all of which were tested in the Malmö Laboratory, are presented in Table 1. Presented are results of the Nijmegen-Bethesda assay and ELISA.

The immunosuppression was tapered until four months later, when it was discontinued because of a postoperative wound infection. At that point FVIII activity was $0.03 \mathrm{IU} / \mathrm{ml}$ with an antibody titre of 3 $\mathrm{BU} / \mathrm{mL}$, while FIX activity was normal $(1.31 \mathrm{IU} / \mathrm{ml})$. In the following three years we observed a spontaneous rise of FVIII activity to a maximum of $0.15 \mathrm{IU} /$ $\mathrm{mL}$, with inhibitor titres falling from 6 to $0.7 \mathrm{BU} /$ $\mathrm{mL}$. During that time the patient suffered only one bleeding, namely haemarthrosis of the left knee, which was treated with 3 doses of NovoSeven.

Because of the patient's constant pain in the left hip, removal of the osteosynthesis material was 
planned. With the intention of preoperative eradication of the remaining inhibitors, four doses of rituximab $375 \mathrm{mg} / \mathrm{m}^{2}$ weekly were prescribed, which ultimately led to a complete eradication of FVIII inhibitors, three years and a half after initial diagnosis.

An inoperable metastatic neuroendocrine microcellular lung carcinoma was diagnosed a year later, causing the patient's death.

\section{Discussion}

With this case report we demonstrate that a patient, initially diagnosed with concurrent inhibitors to both FVIII and FIX, actually had only inhibitors to FVIII. Secondly, we show that clotting assays, such as Bethesda or Nijmegen-modified Bethesda assay can give us false results. We confirm the fact described previously, that an inhibitor to a single clotting factor can interfere with the assays of other coagulation factors, selectively reducing the target factor but there may be some apparent reduction in other factor levels due to an inhibitory effect on the factor deficient plasma used in the assay (5). This is best documented with FVIII inhibitors, where all intrinsic factors may apparently be low due to inhibition of FVIII in the intrinsic factordeficient plasma. In such cases, serial dilution should result in a correction of the non-specifically reduced factors while the specifically reduced factors should remain low $(3,9)$. We have indeed measured decreased FVIII $(<0.01 \mathrm{IU} / \mathrm{mL})$, FIX $(<$ $0.01 \mathrm{IU} / \mathrm{mL}), \mathrm{FXI}(<0.01 \mathrm{IU} / \mathrm{mL})$ and FXII $(0.02 \mathrm{IU} / \mathrm{mL})$ in the initial samples from our patient by using the one-stage aPTT assay.

As the majority of acquired antibodies are directed against FVIII (2), acquired inhibitors to factor IX are only occasionally reported (10-14). Similarly, to FVIII autoantibodies, they seem to occur more frequently in association with autoimmune disorders or postpartum (15). In contrast to FVIII inhibitors, which may show a time dependency for inhibition, FIX inhibitors are immediate-acting $(3,5)$. Initial results of concurrent inhibitors to FVIII and FIX, diagnosed by Bethesda assay (6) in Ljubljana were met with scepticism. However, the finding of dual inhibitors was confirmed in Malmö, using the
Bethesda-Nijmegen assay protocol (7), which is supposed to better discriminate between positive and negative samples at the lower range $(3,9,16)$. Similarly, to results obtained in Ljubljana, FVIII inhibitor titres were much higher (from 73 to $217 \mathrm{BU}$ / $\mathrm{mL}$ ) than FIX inhibitor titres (2.5 to $4 \mathrm{BU} / \mathrm{mL}$ ).

ELISA, performed in a manner previously described (8), using recombinant FVIII or FIX concentrates as antigens, confirmed our assuming that the dual Bethesda positivity was an in vitro finding. The results indicated a strong positivity for antiFVIII IgG, but not for the antibodies against FIX.

According to the literature, false detection of inhibitor antibodies is not so rare, reported in up to $30 \%$ of samples analysed by Nijmegen assay (17) and a common reason for results similar to ours is heparin contamination of the sample (18).

When suspecting an acquired haemophilia, it is also important to rule out lupus anticoagulants as a possible reason for prolonged aPTT $(1,3)$. On the contrary, lupus anticoagulants usually cause thrombosis, not bleeding. They can sometimes mimic FVIII inhibitors, which results in a decrease of most of coagulation factors. An ELISA test for FVIII inhibitor screening is often advised when phospholipid antibodies interfere with the Bethesda assay (4). Favaloro et al. advise using ELISA in all cases in which clot-based assays may be influenced by the presence of other antibodies or by heparin contamination from venous access devices. Clot-based assays are less sensitive than ELISA assays, but the ELISA assays, in contrast, lack specificity because they detect both inhibitory and non-inhibitory (so-called 'non-neutralising') antibodies (17).

Figure 1 demonstrates the measured titres of antiFVIII and anti-FIX antibodies, obtained by using the Bethesda assay in Ljubljana laboratory. A dosedependent effect of anti-FVIII antibodies on the anti-FIX assay can be observed, i.e. the risk of getting false positive anti-FIX results increases with the titre of anti-FVIII inhibitors. In our case the dual positivity (false positive anti-FIX antibodies) is apparent above approx. $110 \mathrm{BU} / \mathrm{mL}$ of anti-FVIII, assuming that the cut-off for positive anti-FIX is 0.6 $\mathrm{BU} / \mathrm{mL}$. A similar graph was obtained using titres 
of antibodies, measured by Nijmegen-Bethesda assay in the Laboratory in Malmö.

To our best knowledge there are only three reports in the literature describing concurrent inhibitors to factor VIII and IX (19-21). Shen et al. described a 14-year-old girl with systemic lupus erythematosus, presenting with ecchymoses and macrohematuria. To attenuate the effect of the FIX inhibitor on the FVIII measurement, the factor assays were repeated at higher serial dilutions of the patient's plasma with FVIII deficient plasma, and vice versa. Inhibitors of FVIII and FIX showed positive findings with 6 and 4 Bethesda units, respectively (19). Brasilian authors presented a case of a 52-year-old man with chronic hepatitis $C$, who received antiviral treatment with pegylated interferon plus ribavirin (20). In this patient, inhibitor antibodies against FVIII were detected in a 70-times higher titre than the inhibitors to FIX. Similarly, to our case, the much lower titre of anti-FIX antibodies could have been an artefact, caused by a disturbance of the Bethesda assay by a high titre of anti-FVIII antibodies. Carmassi and colleagues report a case of a 64-year-old man with a history of cutaneous vasculitis and Sjögren syndrome, presenting with extensive muscular and subcutaneous haematomas. FVIII and FIX activities were 0.05 $\mathrm{IU} / \mathrm{mL}$ and $0.56 \mathrm{IU} / \mathrm{mL}$, respectively, and the corresponding inhibitor titres for FVIII and FIX were 25 $\mathrm{BU} / \mathrm{mL}$ and $7 \mathrm{BU} / \mathrm{mL}$, respectively. To prevent the interference of FVIII inhibitors on FIX, the authors performed the assay at multiple dilutions (21). The ELISA test was not performed in any of the three reports. Our study is yielding possible explanation of the above described results. The strength of our study is utilisation of both the classical Bethesda and the Nijmegen modification of the Bethesda

\section{References}

1. Tiede A, Werwitzke S, Scharf RE. Laboratory diagnosis of acquired hemophilia $A$ : limitations, consequences, and challenges. Semin Thromb Hemost 2014;40:803-11. http:// dx.doi.org/10.1055/s-0034-1390004.

2. Franchini M, Mannucci PM. Inhibitors of propagation of $\mathrm{CO}^{-}$ agulation (factors VIII, IX, and XI): a review of current therapeutic practice. Br J Clin Pharmacol 2011;72:553-62. http:// dx.doi.org/10.1111/j.1365-2125.2010.03899.x. assay; the use of the latter is supposed to reduce weak false positive inhibitor titres. An additional advantage is the utilisation of ELISA, which finally discriminates between truly and falsely positive antibodies.

The limitations of our study are that we did not perform all the tests, since we did not plan to publish the case at that time. In Ljubljana we checked only inhibitors to FVIII and FIX as those are the most common $(15,22)$. When we obtained positive anti-FIX and anti-FXII antibodies by NijmegenBethesda assay, we did not measure anti-FXI antibodies by Bethesda-Nijmegen assay, however we expected them to be positive too. When analysing the "Malmo" patient, we also performed only antiFVIII and anti-FIX antibodies but nothing else after negative anti-FIX by ELISA.

In conclusion, we have shown that anti-FVIII antibodies of a very high titre are capable of disturbing an aPTT-based neutralization assay such as Bethesda, which results in falsely positive antibodies to other coagulation factors. An important message is not to rely on a single Bethesda assay test result. To avoid identification of false inhibitors we must keep in mind that acquired antibodies to FVIII are by far the most common (1). Sometimes a clue for the "true" inhibitor is obtained by the "relative" deficiencies observed (e.g., a FVIII level that is undetectable and detectable but low FIX, FXI and/or FXII is likely to be a FVIII inhibitor) (5). However, this was not the case in our patient. Our case report illustrates the usefulness of immunological assays to complement the inhibitor diagnosis.

\section{Potential conflict of interest}

None declared.

3. Collins PW, Chalmers E, Hart D, Jennings I, Liesner R, Rangarajan $S$, et al. United Kingdom Haemophilia Centre Doctors' Organization. Diagnosis and management of acquired coagulation inhibitors: a guideline from UKHCDO. $\mathrm{Br}$ J Haematol 2013;162:758-73. http://dx.doi.org/10.1111/ bjh.12463. 
4. Shetty S, Bhave M, Ghosh K. Acquired hemophilia A: diagnosis, aetiology, clinical spectrum and treatment options. Autoimmun Rev 2011;10:311-6. http://dx.doi.org/10.1016/j. autrev.2010.11.005.

5. Kershaw G, Favaloro EJ. Laboratory identification of factor inhibitors: an update. Pathology 2012;44:293-302. http:// dx.doi.org/10.1097/PAT.0b013e328353254d.

6. Laffan MA, Manning R. Chapter 18. Investigation of haemostasis. In Bain BJ, Bates I, Laffan MA, Lewis SM Ed. Dacie and Lewis Practical Haematology. 11th edition. London: Elsevier Churchill Livingstone; 2012. p.393-445. http://dx.doi. org/10.1016/B978-0-7020-3408-4.00018-7.

7. Verbruggen B, Novakova I, Wessels H, Boezeman J, van der Berg M, Mauser-Bunschoten E. The Nijmegen modification of the Bethesda assay for factor VIII:C inhibitors: improved specificity and reliability. Thromb Haemost 1995;73:247-51.

8. Klintman J, Hillarp A, Donfield S, Berntorp E, Astermark J. Antibody formation and specificity in Bethesda-negative brother pairs with haemophilia A. Haemophilia 2013; 19:106-12. http://dx.doi.org/10.1111/j.13652516.2012.02903.x.

9. Coppola A, Favaloro EJ, Tufano A, Di Minno MN, Cerbone $A M$, Franchini M. Acquired inhibitors of coagulation factors: part I-acquired hemophilia A. Semin Thromb Hemost 2012;38:433-46. http://dx.doi.org/10.1055/s-0032-1315757.

10. Miller K, Neely JE, Krivit W, Edson JR. Spontaneously acquired factor IX inhibitor in a nonhemophiliac child. J Pediatr 1978;93:232. http://dx.doi.org/10.1016/S00223476(78)80502-2.

11. Mazzucconi MG, Peraino M, Bizzoni L, Bernasconi S, Luciani $M$, Rossi GD. Acquired inhibitor against factor IX in a child: successful treatment with high-dose immunoglobulin and dexamethasone. Haemophilia 1999;5:132. http://dx.doi. org/10.1046/j.1365-2516.1999.00297.x.

12. Berman BW, McIntosh S, Clyne LP, Goldberg B, Lobel J, Komp DM. Spontaneously acquired Factor IX inhibitors in childhood. Am J Pediatr Hematol Oncol 1981;3:77.

13. Krishnamurthy $P$, Hawche $C$, Evans $G$, Winter $M$. A rare case of an acquired inhibitor to factor IX. Haemophilia 2011;17:712-3. http://dx.doi.org/10.1111/j.1365-2516.2010. 02457.x.
14. Largo R, Sigg P, von Felten A, Straub PW. Acquired factor$I X$ inhibitor in a nonhaemophilic patient with autoimmune disease. Br J Haematol 1974;26:129-40. http://dx.doi. org/10.1111/j.1365-2141.1974.tb00456.x.

15. Franchini M, Lippi G, Favaloro EJ. Acquired inhibitors of coagulation factors: part II. Semin Thromb Hemost 2012;38:447-53. http://dx.doi.org/10.1055/s-0032-1305779.

16. Ma AD, Carrizosa D. Acquired Factor VIII Inhibitors: Pathophysiology and Treatment. Hematology Am Soc Hematol Educ Program 2006:432-7. http://dx.doi.org/10.1182/asheducation-2006.1.432.

17. Favaloro EJ, Verbruggen B, Miller CH. Laboratory testing for factor inhibitors. Haemophilia 2014;20:94-8. http://dx.doi. org/10.1111/hae.12408.

18. Favaloro EJ, Bonar R, Duncan E, Earl G, Low J, Aboud M, et al. Mis-identification of factor inhibitors by diagnostic haemostasis laboratories: recognition of pitfalls and elucidation of strategies. A follow up to a large multicentre evaluation. Pathology 2007;39:504-11. http://dx.doi. org/10.1080/00313020701569998.

19. Shen CY1, Fu LS, Lin HK, Han SM, Wang JD. Macrohematuria as initial presentation in a girl with factor VIII and factor IX inhibitors associated with systemic lupus erythematosus. J Pediatr Hematol Oncol 2012;34:344-5. http://dx.doi. org/10.1097/MPH.0b013e3182678ec1.

20. Campos-de-Magalhães M, Eduardo Brandão-Mello C, Lúcia Elias Pires M, Cecília da Fonseca Salgado M, Barcelo de Brito $S$, José de Almeida A. Factor VIII and IX deficiencies related to acquired inhibitors in a patient with chronic hepatitis $C$ virus infection receiving treatment with pegylated interferon plus ribavirin. Hematology 2011;16:80-5. http://dx.doi. org/10.1179/102453311X12902908412156.

21. Carmassi F, Giannarelli C, De Giorgi A, De Negri F. Combined factor VIII and IX inhibitors in a non-haemophilic patient: successful treatment with immunosuppressive drugs. Haemophilia 2007;13:106-7. http://dx.doi.org/10.1111/j.13652516.2006.01352.x.

22. Favaloro EJ, Bonar R, Duncan E, Earl G, Low J, Aboud M, et al. Identification of factor inhibitors by diagnostic haemostasis laboratories: a large multi-centre evaluation. Thromb Haemost 2006;96:73-8. http://dx.doi.org/10.1160/th06-010004. 